\section{Use of tanezumab for patients with hip and knee osteoarthritis with reference to a randomised clinical trial by Berenbaum and colleagues}

Publication spin, in the context of randomised clinical trials, is defined as 'use of specific reporting strategies, from whatever motive, to highlight that the experimental treatment is beneficial, despite a statistically nonsignificant difference for the primary outcome, or to distract the reader from statistically nonsignificant results' (p. 2059). ${ }^{1}$ In our view, a secondary but clinically important alternative type of publication spin is reliance on statistically significant findings without regard to potential clinical implications of the estimated effects. The American Statistical Association (ASA) has commented on this issue, stating a statistically significant effect does not inform its size or importance. $^{2}$ A later editorial more explicitly states that conclusions not be based solely on statistical significance. ${ }^{3}$ We believe the recently published trial by Berenbaum and colleagues ${ }^{4}$ meets our secondary definition of publication spin and does not meet the recommendation endorsed by the ASA.

Berenbaum and colleagues conducted a three-arm phase III randomised clinical trial of two doses of subcutaneously delivered tanezumab (2.5 vs $5 \mathrm{mg}$ ) as compared with placebo, applied to participants with symptomatic hip or knee osteoarthritis (OA). ${ }^{4}$ This trial follows two similarly designed trials conducted on persons with symptomatic hip $\mathrm{OA}^{5}$ or knee OA. ${ }^{6}$ Primary outcomes of the $2020 \mathrm{trial}^{4}$ were the WOMAC Pain Scale (numeric rating version with scores ranging from 0 to 50 with higher scores equating to more severe pain with activity) and the WOMAC Physical Function Scale (scores ranging from 0 to 170 with higher scores equating to more difficulty with activity). The third primary outcome was the five-item Patient Global Assessment of $\mathrm{OA}$ with scores ranging from 1 to 5 with higher scores equating to worse self-reported symptoms and activity limitations.

The abstract reported the following results: 'At week 24, there was a statistically significant improvement from baseline for tanezumab $5 \mathrm{mg}$ compared with placebo for WOMAC Pain (least squares mean difference $\pm \mathrm{SE}-0.62 \pm 0.18, \mathrm{p}=0.0006$ ), WOMAC Physical Function $(-0.71 \pm 0.17, \mathrm{p}<0.0001)$ and PGA-OA $(-0.19 \pm 0.07, \mathrm{p}=0.0051)$. For tanezumab $2.5 \mathrm{mg}$, there was a statistically significant improvement in WOMAC Pain and Physical Function, but not PGA-OA' (p. 1). The conclusion was 'tanezumab $5 \mathrm{mg}$ statistically significantly improved pain, physical function and PGA-OA, but tanezumab $2.5 \mathrm{mg}$ only achieved two co-primary end points' (p. 1).

Treatment effects on primary outcomes were assessed by comparing changes from baseline to a 24 -week follow-up. Mean differences among the three arms was less than one point for all primary outcomes. For WOMAC Pain, mean differences were 0.61 or less compared with placebo, for WOMAC Physical Function, 0.71 points or less compared with placebo and for the global rating measure, 0.18 points or less. Given that the WOMAC Pain Scale ranges from 0 to 50 points and the WOMAC Physical Function Scale ranges from 0 to 170, changes of 0.71 points or less are, in our view, clinically irrelevant. The findings indicate the expected difference is smaller than a patient shifting a response on a single item by one point. We found no discussion of the potential clinical impact of these findings in the paper.
Effects on six secondary outcomes were reported, but our concern with these estimates was that the trial registry listed 59 secondary outcomes with most of these including multiple measures compared over multiple time points. The large number of outcomes tested leads to inflated type I error rates and questions if results were chosen based on the significance.

The adverse effects of tanezumab were quantified in a variety of ways. The abstract emphasised more serious adverse events including rapidly progressive $\mathrm{OA}$ and joint replacement. The investigators reported that 'rapidly progressive osteoarthritis (RPOA) was observed in $1.4 \%(4 / 283)$ and $2.8 \%(8 / 284)$ of patients in the tanezumab $2.5 \mathrm{mg}$ and tanezumab $5 \mathrm{mg}$ groups, respectively and none receiving placebo. Total joint replacements (TJRs) were similarly distributed across all three treatment groups $(6.7 \%-7.8 \%)^{\prime}(\mathrm{p}, 1)$. Given the hypothesised mechanism of action of tanezumab, ${ }^{7}$ the rare but serious complication of rapidly progressive $\mathrm{OA}$ in the active arms and the lack of clinical meaningfulness of the findings, our interpretation differs from that of the investigators. This study indicates to us that tanezumab does not show promise as an effective treatment alternative to more traditional medication for painful knee or hip OA.

\section{Daniel Riddle $\odot,{ }^{1}$ Robert Perera ${ }^{2}$}

'Department of Physical Therapy, Ortho Surgery and Rheumatology, Virginia Commonwealth University, Richmond, Virginia, USA

${ }^{2}$ Department of Biostatistics, Virginia Commonwealth University, Richmond, Virginia, USA

Correspondence to Dr Daniel Riddle, Physical therapy, Ortho Surgery, Rheumatiology, Virginia Commonwealth University, Richmond, VA 23284, USA; dlriddle@vcu.edu

Contributors Both authors contributed to the correspondence letter.

Funding The authors have not declared a specific grant for this research from any funding agency in the public, commercial or not-for-profit sectors.

Competing interests None declared.

Patient and public involvement Patients and/or the public were not involved in the design, or conduct, or reporting, or dissemination plans of this research.

Patient consent for publication Not required.

Provenance and peer review Not commissioned; internally peer reviewed.

(c) Author(s) (or their employer(s)) 2020. No commercial re-use. See rights and permissions. Published by BMJ.

\section{Check for updates}

To cite Riddle D, Perera R. Ann Rheum Dis Epub ahead of print: [please include Day Month Year]. doi:10.1136/annrheumdis-2020-217526

Received 7 April 2020

Accepted 8 April 2020

Ann Rheum Dis 2020;0:1-2. doi:10.1136/annrheumdis-2020-217526

ORCID iD

Daniel Riddle http://orcid.org/0000-0002-3611-2739

\section{REFERENCES}

1 Boutron I, Dutton S, Ravaud P, et al. Reporting and interpretation of randomized controlled trials with statistically nonsignificant results for primary outcomes. JAMA 2010;303:2058-64.

2 Wasserstein RL, Lazar NA. Asa statement on statistical significance and P-values: context, process, and purpose. Am Stat 2016;70:129-33.

3 Wasserstein RL, Schirm AL, Lazar NA. Moving to a World Beyond "p. Am Stat 2019;73:1-19.

4 Berenbaum F, Blanco F, Guermazi A, et al. Subcutaneous tanezumab for osteoarthritis of the hip or knee: efficacy and safety results from a 24-week randomised phase III study with a 24 -week follow-up period. Ann Rheum Dis 2020;0:1-11.

5 Brown MT, Murphy FT, Radin DM, et al. Tanezumab reduces osteoarthritic hip pain: results of a randomized, double-blind, placebo-controlled phase III trial. Arthritis Rheum 2013;65:1795-803. 
6 Brown MT, Murphy FT, Radin DM, et al. Tanezumab reduces osteoarthritic knee pain: results of a randomized, double-blind, placebo-controlled phase III trial. J Pain 2012;13:790-8.
7 Hochberg MC, Tive LA, Abramson SB, et al. When is osteonecrosis not osteonecrosis? adjudication of reported serious adverse joint events in the Tanezumab clinical development program. Arthritis Rheumatol 2016;68:382-91. 